\title{
CAEP 2021 Academic Symposium: recommendations for addressing racism and colonialism in emergency medicine
}

\author{
Jennifer M. Bryan ${ }^{1}$ (D) Sara Alavian² Dawn Giffin $^{3} \cdot$ Constance LeBlanc ${ }^{4} \cdot$ James Liu $^{5} \cdot$ Prashant Phalpher $^{6,7}$. \\ Dominick Shelton ${ }^{8} \cdot$ Judy Morris ${ }^{9} \cdot$ Rodrick Lim $^{10}$
}

Received: 20 October 2021 / Accepted: 29 November 2021 / Published online: 12 January 2022

(c) The Author(s), under exclusive licence to Canadian Association of Emergency Physicians (CAEP)/ Association Canadienne de Médecine d'Urgence (ACMU) 2022

\begin{abstract}
Purpose Racism and colonialism impact health, physician advancement, professional development and medical education in Canada. The Canadian Association of Emergency Physicians (CAEP) has committed to addressing inequities in health in their recent statement on racism. The objective of this project was to develop recommendations for addressing racism and colonialism in emergency medicine.

Methods The authors, in collaboration with a 40 member working group, conducted a literature search, held a community consultation, solicited input from expert medical, academic and community advisors, conducted a national survey of emergency physicians, and presented draft recommendations at the 2021 CAEP Academic Symposium on Equity, Diversity and Inclusion for a live facilitated discussion with a post-session survey.

Results Sixteen recommendations were generated in the areas of patient care, hospital and departmental commitment to Equity, Diversity, and Inclusion, physician advancement, and professional development and medical education.

Conclusion Emergency physicians are uniquely positioned to promote equity at each encounter with patients, peers and learners. The 16 recommendations presented here are practical steps to countering racism and colonialism everyday in emergency medicine.
\end{abstract}

Keywords Antiracism $\cdot$ Anticolonialism $\cdot$ Diversity $\cdot$ Black $\cdot$ Indigenous $\cdot$ BIPOC

\section{Résumé}

Objectif Le racisme et le colonialisme ont une incidence sur la santé, l'avancement des médecins, le développement professionnel et l'éducation médicale au Canada. L'Association canadienne des médecins d'urgence (ACMU) s'est engagée à lutter contre les inégalités en matière de santé dans sa récente déclaration sur le racisme. L'objectif de ce projet était d'élaborer des recommandations pour lutter contre le racisme et le colonialisme en médecine d'urgence.

Méthodes Les auteurs, en collaboration avec un groupe de travail de 40 membres, ont effectué une recherche documentaire, tenu une consultation communautaire, sollicité les commentaires d'experts en médecine, en enseignement et en services

Jennifer M. Bryan

Jennifer.Bryan@utoronto.ca

1 Division of Emergency Medicine, Department of Medicine, University of Toronto, Toronto, ON, Canada

2 Division of Emergency Medicine, Department of Medicine, McMaster University, Hamilton, ON, Canada

3 Department of Emergency Medicine, London Health Sciences Centre, London, ON, Canada

4 Department of Emergency Medicine, Dalhousie University, Halifax, NS, Canada

5 Department of Family Practice, University of British Columbia, Vancouver, BC, Canada
6 Department of Family Medicine, McMaster University, Hamilton, ON, Canada

7 William Osler Health System, Brampton, ON, Canada

8 Department of Family and Community Medicine, University of Toronto, Toronto, ON, Canada

9 Department of Family Medicine and Emergency Medicine, Université de Montréal, Montreal, QC, Canada

10 Department of Paediatrics and Medicine, Western University, London, ON, Canada 
communautaires, mené une enquête nationale auprès des médecins d'urgence et ont présenté des ébauches de recommandations lors du Symposium académique de l'ACMU 2021 sur l'Équité, la Diversité et l'inclusion pour une discussion animée en direct avec un sondage après la séance.

Résultats Seize recommandations ont été formulées dans les domaines des soins aux patients, de l'engagement de l'hôpital et du service en matière d'Équité, de Diversité et d'Inclusion, de l'avancement des médecins, du développement professionnel et de l'éducation médicale.

Conclusion Les médecins urgentistes sont particulièrement bien placés pour promouvoir l'équité à chaque rencontre avec les patients, les pairs et les apprenants. Les 16 recommandations présentées ici sont des mesures pratiques pour contrer le racisme et le colonialisme au quotidien dans la médecine d'urgence.

\section{Background}

Racism and colonialism impact health in Canada [1]. Racism is perpetuation of disparities based on colour or ethnicity. Colonialism is the process whereby the nonIndigenous population engages in practices that assimilate Indigenous populations, ending cultural practices and disrupting ties to land [2].

Black, Indigenous and People of Colour (BIPOC) face determinant of health barriers. Visible minorities have higher prevalence of low-income status, earning less than white counterparts even when accounting for education [3]. Racism itself is a determinant of chronic disease [4].

Canada's colonial history continues to impact racialized communities. Residential schools caused generations of Indigenous people to lose access to culture and suffer abuse, leading to generational trauma [5]. Canada's history of slavery and segregation created a legacy of antiBlack racism; our history also includes Japanese internment, anti-Chinese racism, and many other examples of discrimination [6].

The medical system has perpetuated harm through racism and colonialism, e.g., Indian Hospitals paired promises of healing with forced assimilation [7]. BIPOC patients experience fewer life-saving interventions and poorer health outcomes. In areas with larger First Nations populations, patients with myocardial infarction are $26.9 \%$ less likely to receive revascularization [8]. First Nations people have poorer survival for 14 of 15 common cancers [9]. COVID-19 mortality rates were higher in neighbourhoods with greater Black and racialized populations [10].

The Canadian Association of Emergency Physicians (CAEP) committed to addressing racial health inequities in 2020. This, in part, led to the development of the recommendations presented here.

\section{Methods}

\section{Context}

Three panels were convened for CAEP's 2021 Academic Symposium on Equity, Diversity, and Inclusion (EDI). This is the report of the panel on Antiracism and Anticolonialism. The Gender and LGBTQ2S + panel recommendations are reported separately.

\section{National working group, panel member selection}

Forty practicing physicians, residents and medical students were recruited through CAEP, twenty other associations and social media., prioritizing BIPOC lived experience, and meeting five times over six months. Six working group practicing emergency physicians (EPs) and one emergency medicine (EM) resident committed to authoring the recommendations and being Academic Symposium panelists. We completed a 14-step process including community consultation (Electronics supplementary Material (ESM) Appendix A).

\section{Literature review, national survey, community input}

A scoping review of the literature was conducted with review of grey literature. This informed questions developed for a virtual community forum including more than 40 advocacy groups. A national survey of EPs and learners was conducted (ESM Appendix B) with questions on racial identity adapted from Canadian Institutes for Health Information proposed standards [11] and select physician advancement questions adapted from Mpalirwa et al. [12]. The survey was granted a Research Ethics Board Exemption from University of Toronto as a quality improvement initiative. Consultations were held with community advocates, academic leaders, allied health organizations. Recommendations were developed, reviewed by community members, presented at the Academic Symposium and revised. 


\section{Results}

\section{Literature review}

We identified 25 key existing guidelines and other essential work (ESM Appendix C) and a total of 73 directly relevant documents (ESM Appendix D).

\section{National survey}

There were 270 (247 English, 23 French) respondents. CAEP members (1455) and members of the Canadian emergency medicine community at large (estimated at up to 3500 certified EPs total), were invited to participate (maximal response rate 18.6\%). Most were from Ontario (59.2\%, $142 / 240)$, Québec $(12.9 \%, 31 / 240)$ and British Columbia (7.5\%, 18/240). None were from Prince Edward Island, Yukon or Northwest Territories. Most (184/249, 73.9\%) indicated Canadian ED care is impacted by systemic racism and many $(114 / 249,45.8 \%)$ noted recent impacts of racism or colonialism in their department. They identified a lack of and need for training on culturally safe care. Of the respondents who self-identified as BIPOC (77/236), most had experienced racism at work $(65 / 77,84.4 \%)$. A few participants $(11 / 270,4 \%)$ indicated taking offense to questions about racism and colonialism. Qualitative analysis of text responses suggested a link with lack of awareness of the impacts of racism and colonialism and misconception that supporting BIPOC physicians marginalizes white physicians and decreases care quality.

\section{Community forum and advisor input}

Qualitative analyses of community forum transcripts and advisor meetings identified institutional and systemic factors including the integrity of complaint systems, approaches and barriers to addressing cultural safety, need for professional development and education at all levels of training, and the importance of BIPOC representation in policy formation and as part of ED teams.

\section{Symposium presentation}

There were 74 attendees at the symposium. 56 responded to an in-session questionnaire: $75 \%$ (42/56) staff physicians, $23 \%(13 / 56)$ other health professionals, medical students or residents, and one community member. Nearly half $(45 \%$, 25/56) identified as BIPOC. Topics raised included the importance of training, addressing biases, sharing interpretation practices, avoiding tokenism, and how to value lived experience without violating charter rights during interviews (trainee and staff levels). Fifteen participants completed a follow-up survey on the importance and practicality of recommendations guiding further revisions.

\section{Recommendations}

\section{Patient care (Box 1a)}

Box 1a Patient care recommendations for addressing racism and colonialism in emergency medicine

1. Be aware of the impact of racism and colonialism on health care and adopt strategies to mitigate their effects

2. Provide care using the patient's preferred language

3. Use a trauma-informed approach in interactions with all patients to increase patient engagement and reduce the risk of re-traumatization

4. Learn about legislation, key reports and government services relevant to the care of Indigenous patients

5. Support BIPOC parents in parenting their own children. Be aware of the historical separation of Indigenous families, the ongoing overrepresentation of BIPOC families in the child welfare system, and the trauma associated with separating families during times of crisis

6. Recognize that involvement of security and police can have disproportionate impacts on BIPOC patients

Recommendation $1 \mathrm{Be}$ aware of the impact of racism and colonialism on health care and adopt strategies to mitigate their effects.

Biases are common and are associated with diagnostic and management errors. BIPOC patients are at risk of being under-triaged, not receiving advanced investigations, having inadequate pain management, insufficient consent processes and underrecognized and undertreated mental health concerns [1]. EPs must recognize this to apply mitigation strategies. EPs should consider each patient as an individual rather than representing their community. EPs should use standardized risk stratification tools and pain rating scales and ensure that a complete informed consent process is undertaken with support persons and interpreters as needed. Respect patients' traditional healing practices. Avoid discouraging traditional food intake, support from Elders and land-based healing. Consider determinants of health in management plans and become familiar with supports for specific patient groups. Mitigate the impact of limited primary care access by making necessary referrals and connecting patients with community resources.

Recommendation 2 Use Trauma-Informed-Care [13] in interactions with all patients to increase patient engagement and reduce the risk of re-traumatization. 
Consider earning trust as an objective, not an expectation. Power differentials between patients and EPs may impair communication, exacerbate trauma, and contribute to care avoidance. Invite patient input, listen to feedback and avoid using an authoritarian tone. Respect patient dignity. Speak with and about patients respectfully. Protect their privacy. Planning for additional time may reduce frustration and create space for addressing needs. Adopt a low-barrier and harm-reduction approach. Avoid termination of care due to perceived non-adherence. Psychiatric assessments in particular must incorporate recognition of the complex role of stigma and racism in mental health related ED presentations.

Recommendation 3 Provide care using the patient's preferred language.

Language is tied to culture; interpretation goes beyond literal translation. EDs should have $24 \mathrm{~h}$ access to interpretation, including American Sign Language and Quebec Sign Language in person, by phone or online. Interpretation should be offered to all patients whose primary language is different than the provider's. Avoid reliance on informal interpretation by staff not in the circle of care. Interpretation by patient family and friends increases risk of suboptimal care through misunderstandings, missing sensitive information, compromised privacy and independence. Interpretation use should be tracked and feedback solicited from patients about interpretation needs being met. Department signage and written information should be available in the languages of the communities served.

Recommendation 4 Learn about legislation, key reports and government services relevant to the care of Indigenous patients.

Be familiar with the Calls to Action of the Truth and Reconciliation Commission [5] and final report of the National Inquiry into Missing and Murdered Indigenous Women and Girls [14]. Learn about Jordan's Principle (the agency of first contact has responsibility to provide First Nations children with necessary and timely care despite jurisdictional conflicts) [15]. Be familiar with the Non-Insured Health Benefits program (NIHB) to support patient access to benefits [16].

Recommendation 5 Support BIPOC parents in parenting their own children. Be aware of the historical separation of Indigenous families, the ongoing overrepresentation of BIPOC families in the child welfare system, and the trauma associated with separating families during times of crisis.

Family members are key on a child's care team; children should not be separated from families to receive health care. Initiatives such as the \#aHand2Hold campaign [17] exemplify the advocacy role EPs can adopt. BIPOC children are over-represented in child welfare systems [18]. Carefully consider whether Child Protection Services involvement is in the child's best interest, and not informed by bias.
Recommendation 6 Recognize that involvement of security and police can have disproportionate impacts on BIPOC patients.

Involving security and police increases the risk of patient ED removal prior to provision of adequate medical care and may increase risk of injury or mortality for BIPOC patients [19]. Use de-escalation techniques and prioritize patients' needs when faced with patient frustration and agitation. EDs should ensure that security personnel receive longitudinal cultural safety training and that there are regular reviews of security practices.

\section{Hospital and departmental commitment to EDI (Box 1b)}

Box 1b Hospital and departmental commitment to EDI recommendations for addressing racism and colonialism in emergency medicine

\footnotetext{
7. Incorporate reconciliation and health equity in all department undertakings, including the strategic plan, built environment, and metrics of department and leadership success

8. Emergency departments should collect and use equity data to improve care following established ethical frameworks

9. Ensure clear accountability in complaints processes

10. Actively engage stakeholders from BIPOC communities in emergency department programs
}

Recommendation 7 Incorporate reconciliation and health equity in all department undertakings, including the strategic plan, built environment, and metrics of department and leadership success.

Hospitals and EDs need clear strategies for measuring equity initiative outcomes and transparent accountability approaches. EDI should be incorporated in patient safety, quality improvement (PSQI), and research initiatives, including Patient Reported Outcome Measures (PROMs). Support Indigenous healing practices (e.g., smudging) in policy and in the ED built environment. Integrate EDI in performance reviews, professional development plans and remediation. ED leadership should be aware of the risk of backlash for EPs engaging in EDI work and mitigate this through explicit support and recognition.

Recommendation 8 EDs should collect and use equity data to improve care following established ethical frameworks.

Equity data, including race and indigeneity, can be used to identify health disparities but have also been used to harm members of BIPOC communities. EDs should look to the equity data collection framework being developed by CIHI [11] and the principles of OCAP (ownership, control, access, and possession) [20] and EGAP (engagement, governance, access and protection framework) [21] for responsible data 
collection and use in collaboration with communities. Use this data to perform periodic reviews of triage accuracy, pain control and other care metrics to identify disparities.

Recommendation 9 Ensure clear accountability in complaints processes.

Hospitals and EDs should have autonomous ombudspersons and transparent confidential complaint processes including whistleblower protection and a 'no wrong door policy' for any staff member to initiate complaints processes. Prioritize expertise and lived experience in complaint response roles. Racism alone is a valid basis for complaint. Complaints should be tracked and periodic surveys of staff, patients and learners undertaken. EDs and individual EPs should publicly commit to working towards equity. A zero tolerance policy for discrimination should appear prominently in ED signage.

Recommendation 10 Actively engage stakeholders from BIPOC communities in ED programs.

Adopt community-led approaches to identify stakeholders, set equity goals and determine community representative compensation (financial or in-kind). Stakeholders may include local Indigenous governments, Elders, social service organizations, patient groups and other representatives, recognizing the diversity within and between BIPOC communities. Partnership agreements should include process evaluations, accountability measures, and celebrations of success. Community patient advocates should be recruited, trained and supported as patient liaisons and health navigators.

\section{Physician advancement (Box 1c)}

Box 1c Physician advancement recommendations for addressing racism and colonialism in emergency medicine

11. Recruit staff physicians and residents from groups underrepresented in medicine

12. Emergency departments should actively engage in equity-based pipeline mentorship activities

13. Actively support the retention and promotion of BIPOC physicians through inclusivity, mentorship and meaningful recognition of work in EDI

Recommendation 11 Recruit staff physicians and residents from groups underrepresented in medicine.

A racially diverse EP complement is directly related to better care for BIPOC patients [22]. BIPOC lived experience is a valuable source of knowledge clinically and in medical education. Actively recruit a diverse physician group, at minimum aiming to mirror community racial composition. Invite applications from underrepresented groups in job postings, advertise with equity based organizations (e.g.,
Indigenous Physicians Association of Canada, Black Physicians of Canada). Encourage individual candidates directly and include BIPOC representation on recruitment and promotion committees. Track recruitment/ promotion metrics for BIPOC EPs, including residency program applicant demographics, interview rate and position offers to identify staffing and recruitment gaps.

Recommendation 12 EDs should actively engage in equity-based pipeline-mentorship activities.

Pipeline-mentorship builds the pool of future EPs, particularly at medical school and postgraduate levels. EDs should develop post-graduate mentorship programs to foster career development, with special consideration for BIPOC residents. EPs should be encouraged and incentivized to mentor, to provide academic supervision, to consider employing BIPOC learners at all levels and to participate in existing initiatives for increasing representation of BIPOC students in medical school and to create them where they do not exist.

Recommendation 13 Actively support the retention and promotion of BIPOC physicians through inclusivity, mentorship and meaningful recognition of work in EDI.

EDs should avoid tokenism by valuing staff from underrepresented groups through mentorship, sponsorship, and coaching opportunities. New BIPOC EPs should be paired with a physician advocate to review career goals and for support in promotion processes. Track and publicize recruitment and promotion metrics for BIPOC EPs. Physician remuneration should not be impacted by incorrect assumptions about differential taxation rates for Indigenous physicians.

\section{Professional development and medical education (Box 1d)}

Box 1d Professional development and medical education recommendations for addressing racism and colonialism in emergency medicine

14. Undertake antiracism and Indigenous cultural safety education including training on Trauma Informed Care

15. Revise current education curricula and assessment tools to eliminate perpetuation of stereotypes and misrepresentation of race as a disease risk factor

16. Implement EDI education initiatives for members of hiring, awards, promotion, conference and event planning committees

Recommendation 14 Undertake antiracism and Indigenous cultural safety education including training on Trauma-Informed-Care.

EPs should undergo education on topics including Indigenous history, generational trauma, colonialism, systemic racism and impacts on health/ ED care, tools for identifying 
personal biases, barriers to health equity, Trauma-InformedCare[13], and allyship. Curriculum on epigenetics of trauma should be integrated as this science evolves. Use established programs delivered longitudinally in collaboration with local BIPOC communities, recognizing that antiracism education is a lifelong endeavor.

Recommendation 15 Revise current curricula and assessment tools to eliminate perpetuation of stereotypes and misrepresentation of race as a disease risk factor.

Curriculum misrepresenting race as a biological category rather than a social construct perpetuates racism and racebased diagnostic biases. Education reform should begin with a common framework across curricula for addressing race, ethnicity and the ongoing effects of racism and colonialism. Assessments should be re-developed to eliminate implicit bias. OSCE and oral examinations that incorporate BIPOC content with input from BIPOC physicians, patients, and community advocates should be developed and shared nationally.

Recommendation 16 Implement EDI education initiatives for members of hiring, awards, promotion, conference and event planning committees.

Hiring, awards, promotion, conference and event committees should be educated on the importance of EDI. Postgraduate programs should employ an EDI lens for assessing applications to minimize bias. Such measures include selection committee anti-bias training, transparent application criteria and ranking processes, valuing non-academic activities such as community advocacy and grassroots organizing and recognizing "distance travelled" in overcoming barriers during medical school including financial need and lack of healthcare mentors.

\section{Limitations}

These recommendations do not address discrimination due to disability, religion, legal status in Canada, or age. They also do not specifically address intersectionality, how experiences are shaped by overlapping identity in groups. Further, there are important distinctions between the many groups included under the term "BIPOC". Each of these topics warrant dedicated individual consideration not possible within the scope of these recommendations but all are important areas for future work.

\section{Conclusion}

These are 16 key recommendations for addressing patient care, hospital and departmental commitment to EDI, physician advancement, and professional development and medical education. Practical steps towards antiracism and anticolonialism are overdue in EM. EPs have the opportunity at each interaction with patients, peers and learners to counter the impacts of discrimination and systemic racism.

Supplementary Information The online version contains supplementary material available at https://doi.org/10.1007/s43678-021-00244-2.

Acknowledgements The authors gratefully acknowledge three key community advisors who provided input in the creation of these recommendations based on their lived experience and expertise: Ms. Eileen Gelowitz, Mr. Lyndon George, and Mr. Brad McCannell and the Rick Hansen Foundation. We also acknowledge the other valued community members who shared their stories and input in community forums over the past year. The authors also acknowledge the input of the following individuals and groups who provided feedback at various stages of this work: The HEAR Team (in particular, Joyla Furlano, Hannah Healey, and Dr. Lloy Wylie), Dr. Darlene Kitty, Dr. Onye Nnorom, Dr. Evan Adams, Dr. OmiSoore H. Dryden, and Mr. Tom Taggart (Paladin Security Group Ltd). We also extend our gratitude to the many emergency physicians, residents, students and allies who completed the national survey, participated in the recommendations working group or otherwise made the development of these recommendations possible, especially: Dr. Terri Aldred, Dr. Amir Ali, Dr Jenwa Beaupré, Dr. Kathryn Chan, Dr. Jim Christenson, Dr. Evelyn Dell, Dr. Michelle Firestone, Ms. Suzanne Elizabeth George, Dr. Sahil Gupta, Dr. Kate Hayman, Dr. Jennifer Hulme, Dr. Steve Lin, Dr. Taylor Lougheed, Dr. Kelsey MacLeod, Dr Sean Moore, Dr. Nicole Nitti, Dr. Dillan Radomske, Dr. Saleem Rezack, Dr. Eric J Smith, Dr. Telisha Smith-Gorvie, and Dr. Jennifer Clara Tang.

Funding Funding for community advisor honoraria was provided by the Canadian Association of Emergency Physicians.

Conflicts of interest The authors would like to acknowledge the $\mathrm{Ca}$ nadian Association of Emergency Physicians (CAEP) for providing administrative support in completing this work and for providing community advisor honoraria.

\section{References}

1. Allan B, Smylie J. First Peoples, second class treatment: The role of racism in the health and well-being of Indigenous peoples in Canada. The Wellesley Institute, 2015. https://www.wellesleyi nstitute.com/wp-content/uploads/2015/02/Summary-First-Peopl es-Second-Class-Treatment-Final.pdf. Accessed 29 Sep 2021.

2. Canadian Heritage. Building a Foundation for Change: Canada's Anti-Racism Strategy 2019-2022. 2019. https://www.canada.ca/ en/canadian-heritage/campaigns/anti-racism-engagement/anti-racism-strategy.html\#a8. Accessed 16 Sep 2021.

3. Statistics Canada. Table 14-10-0359-01: Labour force characteristics by Indigenous group and educational attainment. 2021 https://www150.statcan.gc.ca/t1/tbl1/en/tv.action?pid=14100 35901. Accessed 16 Sep 2021.

4. Siddiqi A, Shahidi FV, Ramraj C, Williams DR. Associations between race, discrimination and risk for chronic disease in a population-based sample from Canada. Soc Sci Med. 2017;194:135-41.

5. Truth and Reconciliation Commission of Canada. Calls to Action. 2015.

6. Backhouse C. Colour coded: A legal history of racism in Canada, 1900-1950. University of Toronto Press. 1999. https://tspace.libra ry.utoronto.ca/bitstream/1807/101779/1/Colour_Coded_UTP_ 9781487527860.pdf. Accessed 1 Nov 2021. 
7. Lux MK. Care for the 'racially careless': Indian hospitals in the Canadian west, 1920-1950s. Can Hist Rev. 2010;91(3):407-34.

8. Alter DA, Tu JV, Austin PC, Naylor CD. Waiting times, revascularization modality, and outcomes after acute myocardial infarction at hospitals with and without on-site revascularization facilities in Canada. J Am Coll Cardiol. 2003;42(3):410-9.

9. Withrow DR, Pole JD, Nishri ED, Tjepkema M, Marrett LD. Cancer survival disparities between first nation and non-aboriginal adults in Canada: follow-up of the 1991 census mortality cohort. Cancer Epidemiol Biomark Prev. 2017;26(1):145-51.

10. Subedi R, Greenberg L, Turcotte M. COVID-19 mortality rates in Canada's ethno-cultural neighbourboods. 2020. https://www150. statcan.gc.ca/n1/pub/45-28-0001/2020001/article/00079-eng.htm. Accessed 16 Sep 2021.

11. Canadian Institutes for Health Information. Proposed standards for race-based and Indigenous identity data collection and health reporting in Canada. 2020. https://www.cihi.ca/sites/default/ files/document/proposed-standard-for-race-based-data-en.pdf. Accessed 29 Sep 2021.

12. Mpalirwa J, Lofters A, Nnorom O, Hanson MD. Patients, pride, and prejudice: exploring Black Ontarian physicians' experiences of racism and discrimination. Acad Med. 2020;95(11S):S51-7.

13. BC Provincial Mental Health and Substance Use Planning Council. Trauma-Informed Practice Guide. 2013. https://bccewh.bc. ca/wp-content/uploads/2012/05/2013_TIP-Guide.pdf. Accessed 16 Sep 2021.

14. National Inquiry Into Murdered and Missing Indigenous Women and Girls. Reclaiming power and place: Calls for justice. 2019. https://www.mmiwg-ffada.ca/final-report/. Accessed 15 Sep 2021.
15. Indigenous Services Canada. Jordan's principle. 2021. https:// www.sac-isc.gc.ca/eng/1568396042341/1568396159824. Accessed 17 Sep 2021.

16. Indigenous Health Services. Non-insured health benefits for First Nations and Inuit. 2020. https://www.sac-isc.gc.ca/eng/15725 37161086/1572537234517. Accessed 17 Sep 2021.

17. Shaheen-Hussain S. Fighting for a Hand to Hold: Confronting Medical Colonialism Against Indigenous Children in Canada. McGill-Queen's Press-MQUP; 2020.

18. Ontario Human Rights Commission. Interrupted childhoods: Over-representation of Indigenous and Black children in Ontario child welfare. 2018. http://www.ohrc.on.ca/en/interrupted-child hoods. Accessed 17 Sep 2021.

19. Maynard R. Policing Black lives: state violence in Canada from slavery to the present. Nova Scotia: Fernwood Publishing; 2017.

20. First Nations Information Governance Centre. The First Nations Principles of OCAP. 2015. https://fnigc.ca/ocap-training/. Accessed 16 Sep 2021.

21. Black Health Equity Working Group. Engagement, Governance, Access, and Protection (EGAP): A Data Governance Framework for Health Data Collected from Black Communities in Ontario. 2021. https://blackhealthequity.ca. Accessed 16 Sep 2021.

22. Arno K, Davenport D, Shah M, Heinrich S, Gottlieb M. Addressing the urgent need for racial diversification in emergency medicine. Ann Emerg Med. 2021;77(1):69-75. 